\title{
Preliminary numerical studies conducted for the numerical model of a real transpired solar collector with integrated phase changing materials
}

\author{
Andrei - Stelian Bejan ${ }^{1,2, *}$, Cristiana Verona Croitoru ${ }^{1,2}$, Florin Bode $^{2,3}$ \\ ${ }^{1}$ Technical University of Civil Engineering Bucharest, Faculty of Engineering for Building Services, 021407 Bucharest, Romania \\ ${ }^{2}$ CAMBI Research Centre, 021407 Bucharest, Romania \\ ${ }^{3}$ Technical University of Cluj-Napoca, 400114 Cluj-Napoca, Romania
}

\begin{abstract}
Solar energy has a great potential to reduce the worldwide energy consumptions thus mitigating the impact of building systems on the global warming. Transpired solar collectors (TSC) are cost-effective solutions and phase changing materials (PCM) implemented within them could store the energy during the periods when solar radiation is available. The current paper is part of comprehensive numerical studies and analyses the mesh independency studies conducted in ANSYS Fluent with SST k- $\Omega$ viscous model and the numerical model preliminary results $\left(3.3^{\circ} \mathrm{C}\right.$ rise in temperature). The results emphasise that the 5 million cells mesh is the feasible option for the studied case.
\end{abstract}

\section{Introduction}

\subsection{Current state of the art}

Given the current global energy context and the fact that buildings are responsible for more than one third of worldwide $\mathrm{CO} 2$ emissions [1] it is mandatory to use systems which are based on renewable energy sources (RES) in order to achieve the indoor comfort parameters with lower energy consumptions.

Solar energy is one of the most promising RES and solar collectors (SCs) are already used on a large scale, especially the water based solar collectors (WSCs). A solution that is less known by the RES market is represented by air solar collectors (ASCs) which have the advantage of no risk of frost during the winter in colder regions, a lower impact on the environment and lower investment and operational costs [2].

ASCs can be classified as opaque solar collectors (OSCs) and glazed solar collectors (GSCs) [3]. Several types of OSCs were studied and found in literature $[4,5]$, but those that stand out are SCs with plane absorber plate, SCs with transpired solar plate or SCs where the opaque absorber plate is protected by a glass layer. Regarding the low-temperature applications, the transpired solar collectors (TSCs) are most likely to be used [6] and have lower costs over the lifetime.

TSCs are promising solar energy solutions and could represent a sustainable alternative strategy used in order to mitigate energy consumptions for space heating or preheating the fresh air [7]. Moreover, according to the literature, TSCs could be used for drying solutions, maintaining a safety minimum indoor temperature in warehouses or improving the HVAC systems overall efficiency $[8,9]$. According to Leon and Kumar (2017) TSCs implemented so far can determine an outlet air temperature between $27^{\circ} \mathrm{C}$ and $70^{\circ} \mathrm{C}$ and could reach an efficiency up to $72 \%$ [10].

Many research studies are focused on the geometry of the SCs, on their absorbent plate characteristics, airflow, orifices pitch, but there very few studies regarding the improvement of the orifices geometry, which are usual circular shaped. Many studies were conducted lately on the lobed geometries [11-13]. The geometry of the orifices can determine an important impact on the TSCs efficiency because $28 \%$ of the thermal energy is transferred to the air in the absorbent plate holes [14]. Moreover, previous studies shows that lobed orifices can provide a higher exhaust air temperature (with more than $2^{\circ} \mathrm{C}$ ), can determine an higher efficiency of the TSC (with up to $15 \%$ for $80-220$ $\mathrm{m} 3 / \mathrm{h} / \mathrm{m} 2$ airflow) and a higher heat transfer (with up to $40 \%)[15,16]$.

One of the main issues of the RESs is their instability and dependency of the outdoor climate. This is why, in order to store the surplus energy produced during the periods when solar radiation is available (during the day), it is essential to implement thermal energy storage (TES) materials [17]. In this way, the accumulated energy could be used during the cloudy periods or during the night when the solar radiation is lower or nonexistent, thus increasing the collectors' overall efficiency, number of hours of functioning and outlet temperature variation [18].

One of the TES materials that can store a great amount of energy (sensible and latent) unlike classical thermal mass materials are the phase changing materials

\footnotetext{
"Corresponding author: andrei.s.bejan@gmail.org
} 
(PCMs) [19]. According to the extensive bibliographic studies analysed, TSCs with integrated TES materials have been scarcely studied, and moreover we did not identify any studies regarding the implementation of PCMs within TSCs.

\subsection{Methodology and studies objective}

Our studies are focusing on the implementation of PCMs within TSCs with lobed orifices with the main objective to capture as much solar energy as possible during the daytime. After experimental studies conducted on the real scale collector presented in Figure 1 and Figure 2, we decided to build a numerical model in order to optimize its geometry and characteristics using Ansys Fluent CFD software which is, according to the literature, widely used for the ASCs modelling and phase change phenomena $[20,21]$.
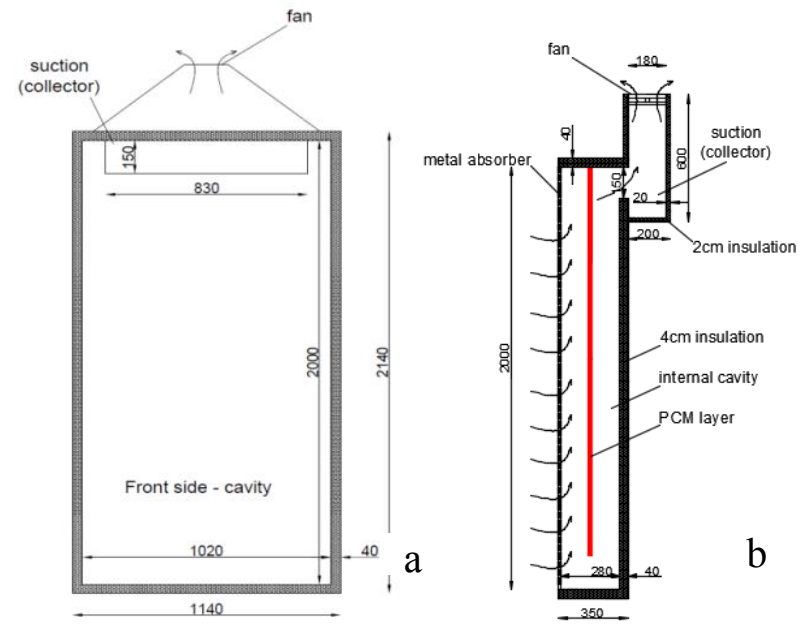

Fig. 1. The geometry of the TSC: a-front view, b-section.
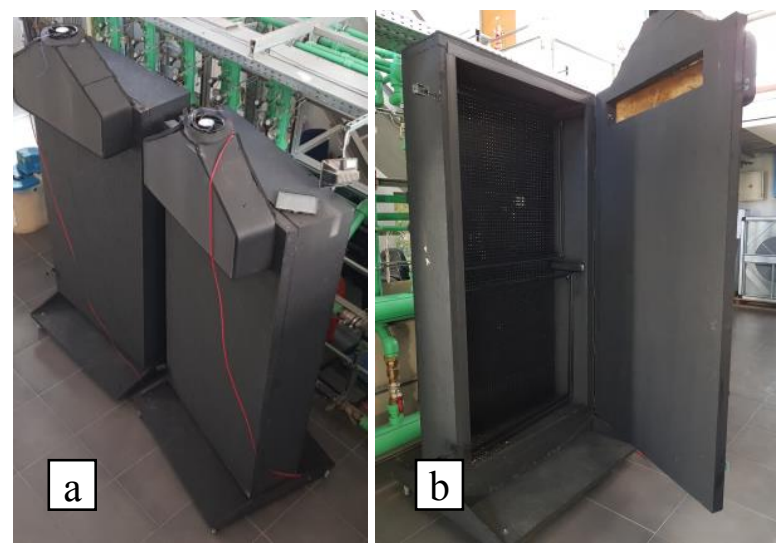

Fig. 2. Real scale TSC: a-overview, b-interior

The solar radiation is captured by the absorbent plate with lobed orifices and transferred to the air aspired in the first air cavity. The airflow is forced to the downer part of the TSC by the PCMs obstacle that stores/releases the energy depending of the climate conditions and building needs, and then it is transferred to the second air cavity were gains an ascendant trajectory. Before being exhausted by a centrifugal ventilator, the air is collected in a plenum (collector), which acts like a mixing box.

The geometrical characteristics of the TSC with integrated PCMs and the materials used are widely presented in the literature $[22,23]$.

At the beginning of the numerical modelling process, we have decided to simulate the entire solar collector metal absorber. Because of the large number of lobed orifices (5000) and their complex geometry, we have obtained a large number of meshing cells that determines high computational resources and requires a couple of months needed in order to compute.

This is why we decided first to model the airflow through four equivalent orifices of the metal absorber and to determine the airflow parameters (mainly velocity fields and temperature fields) at ten equivalent diameters (10De) distance from the metal plate $(5 \mathrm{~cm})$. The mesh independency study results [22] and the validation of the this numerical model [23] were analysed before and their results will be used for the current paper (the outlet of the previous model becomes the inlet of the current model).

The present paper main objective is to analyse the mesh independency study of the real scale TSC using both qualitative and quantitative approach and its preliminary results in steady state regime. The software used for the numerical simulation is ANSYS Fluent, which is one of the most used CFD software based on the finite volume methods that splits the entire volume in small volumes (determining a spatial mesh). The hardware used for computation is one server from the Faculty of Building Services Engineering (TUCEB) laboratories: Dual processor Intel Xeon $3.4 \mathrm{GHz}, 16$ cores and 128 GB RAM.

\section{Materials and methods}

\subsection{Geometry of the numerical model}

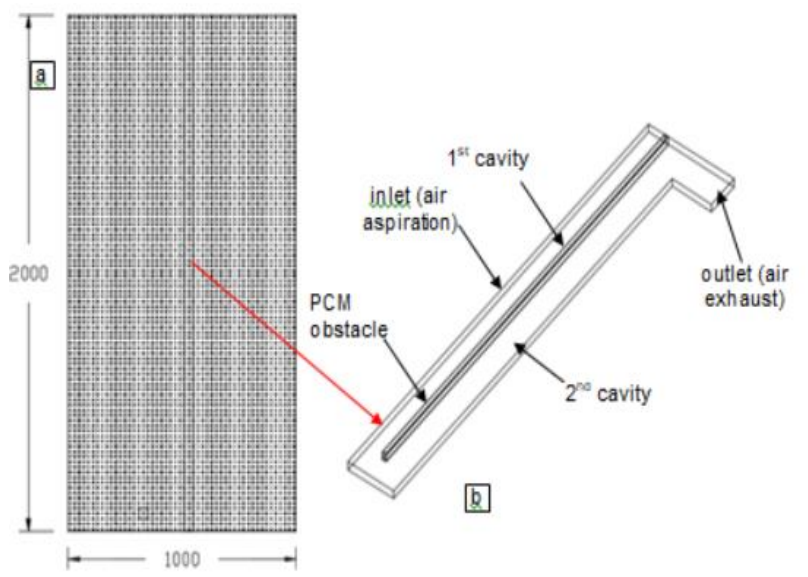

Fig. 3. Designing the geometry in AutoCAD: a - absorbent plate with lobed orifices, $b$ - extraction of a "slice" from the solar collector and its components

In order to achieve the numerical simulations within a feasible time, we decided to simplify the real geometry, starting from the premise of the symmetry of the 
phenomena that are composing the entire collector. Figure 3 shows the absorbent plate through which ambient air is aspired into the solar collector cavity.

As we highlighted earlier, in order to perform numerical simulation for the entire geometry the number of the elements will be very high as well as the computation resources, we choose to study a relevant slice of the presented geometry. From this we extracted a row of orifices (Figure 3a), resulting a transversal "slice" through the real scale solar collector (Figure 3b). Aspiration (collectors' inlet) is composed of 50, $4 \times 4$ metal plates previous studied [23] and it is $4 \times 200 \mathrm{~cm}$. The air circulated through the collector (with the properties set at 10De) is "aspired into the model", enters the cavity between the metal plate and the PCMs obstacle and continues its downstream trajectory.

After designing the SC geometry in the AutoCAD design software, the 3D model was imported into ANSYS DesignModeler (Figure 4).

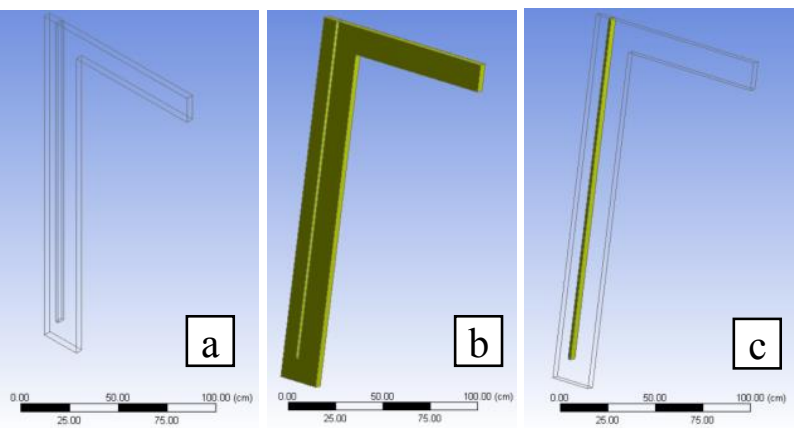

Fig. 4. Importing the geometry from AutoCAD to ANSYS DesignModeler: a-isometric view, b-body corresponding to the air cavity, c-PCM body

After creating the geometry in ANSYS and defining the bodies (Figure 4), the inlet of the solar collector was divided into 50 faces $(4 \times 4 \mathrm{~cm})$ in order to integrate the velocity fields obtained at $10 \mathrm{De}$ from the lobed plate studied before (Figure 5).

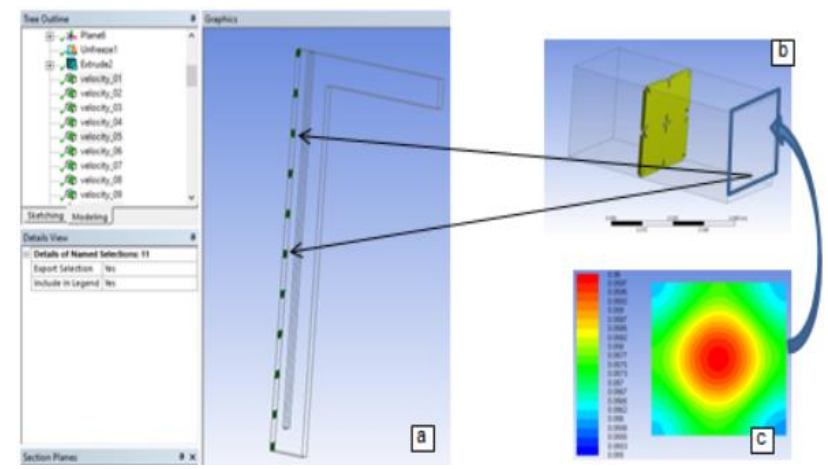

Fig. 6. Creating specific air intake areas (inlet) where the velocity and temperature profiles from the previous studies can be entered as boundary conditions: $a-50$ zones on the inlet; $b$ - the outlet of the previous study became the inlet of the new study; c - velocity field which will be integrated on the new inlet [23]

\subsection{Meshing}

After the proper construction of the geometry, the next step of the numerical modelling is choosing the relevant computational grid. Moreover, in order to determine the number of the elements (cells) needed to solve the problem, it is necessary to make a solution independency study with respect to the quality of the meshing.

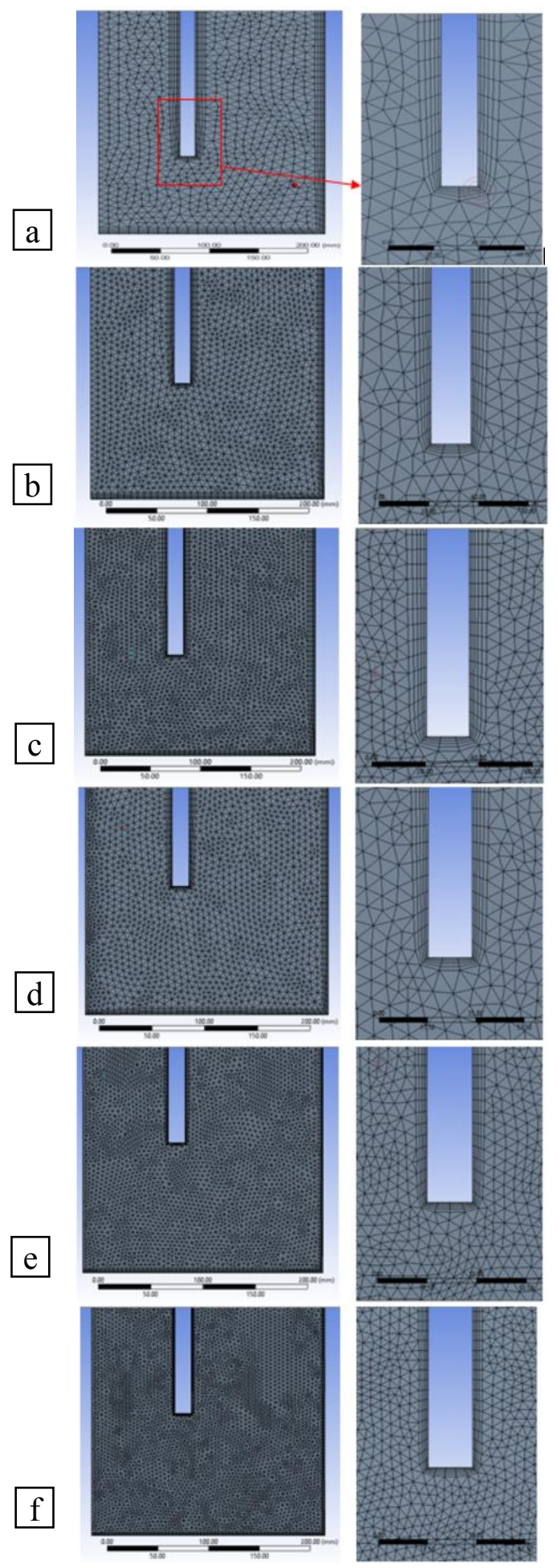

Fig. 6. Meshing levels for the analysed cases without PCM: a) $0.2(0.18)$, b) $0.66(0.61)$, c) $1.3(0.7)$, d) $2.8(1)$, e) $5(2.5)$, f) 6 (3.5) million elements 
In order to conduct the mesh independency study we chose six meshing levels, respectively: $0.2,0.66,1.3$, 2.8, 5 and 6 million cells.

In order not to carry out the mesh study in transient regime, which would substantially extend the time needed for the present study, we decided to remove the PCM layer from the model and carry out the study in steady state regime, because we wanted to acknowledge the quality of the mesh related with the studied airflow field. This will not affect the final results because we aim to study the airflow through the solar collector with PCMs and the resulting temperatures (and not the phenomena that occur in the PCMs cavity). By extracting the PCM cavity form the entire geometry, results the following meshing levels: $0.18,0.61,0.7,1$, 2.5 and 3.5 million.

The meshing levels are shown in Figure 6 and we can observe the gradual increase in the concentration of meshing elements, especially in the boundary layer. The optimal meshing level is determined by individual numerical simulations, using boundary conditions and identical case setups.

\subsection{Boundary conditions and case setup}

The six meshing levels (Figure 6) were then imported into ANSYS Fluent and for each of them the same boundary conditions were imposed, which are shown in Table 1 . The inlet air velocity corresponds to the velocity profiles calculated in the previous conducted study [23] and has values ranging from 0.055 to $0.06 \mathrm{~m} / \mathrm{s}$ for each of the 50 faces, resulting a total velocity on the transversal "slice" (inlet) of about $2.75 \mathrm{~m} / \mathrm{s}$. The temperature of the air at the inlet (at $10 \mathrm{De}$ ) is $26^{\circ} \mathrm{C}$ and the temperature of the wall that separates the PCMs layer to the cavity is $40^{\circ} \mathrm{C}$. These assumptions represent the cooling stage, respectively the heat transfer from the PCMs to the airflow in periods when the solar radiation is not available. The areas where the boundary conditions were imposed are presented in Figure 7 and the velocity fields imported from the previous model studied [23] are shown in Figure 8.

Table 1. Boundary conditions used for the mesh independency study

\begin{tabular}{|c|c|c|}
\hline Boundary condition & Value & Unit \\
\hline Inlet temperature (inlet) & 26 & ${ }^{\circ} \mathrm{C}$ \\
\hline $\begin{array}{c}\text { PCM temperature (wall } \\
\text { between the PCM and cavity) }\end{array}$ & 40 & ${ }^{\circ} \mathrm{C}$ \\
\hline & $\begin{array}{c}\text { Velocity field obtained from } \\
\text { the previous study with } \\
\text { values between 0.055-0.06 } \\
\text { Average velocity (inlet) }\end{array}$ & $\begin{array}{c}\mid c \text { all 50 faces on the } \\
\text { inlet }\end{array}$ \\
\hline
\end{tabular}

The velocity field obtained at 10De from the previous studies was imported in the Tecplot data processing software (Figure 9). On this we created a matrix of points that were subsequently exported to text editor software and processed in $\mathrm{X}, \mathrm{Y}$, and $\mathrm{Z}$ coordinates so that they could fit into the new model's coordinates. The newly created profiles were subsequently imported and retrieved under the boundary conditions in the inlet area. In addition to the energy conservation model, I chose the SST k- $\Omega$ turbulence model (with corrections for a small Reynolds numbers as the case studied and curvature corrections etc.). This is one of the most feasible turbulence models and is suitable, according to the literature, for small Reynolds numbers [24] and for airflows within rectangular air cavities [25].

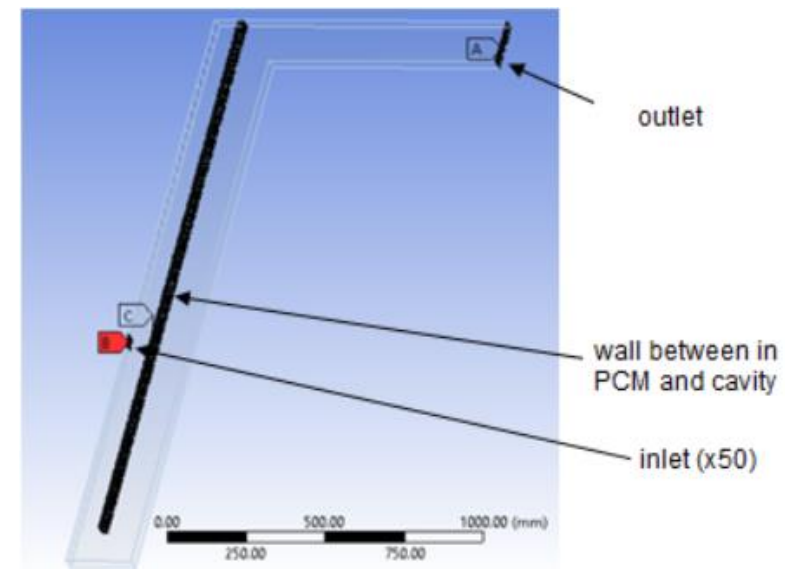

Fig. 7. Areas where boundary conditions were imposed

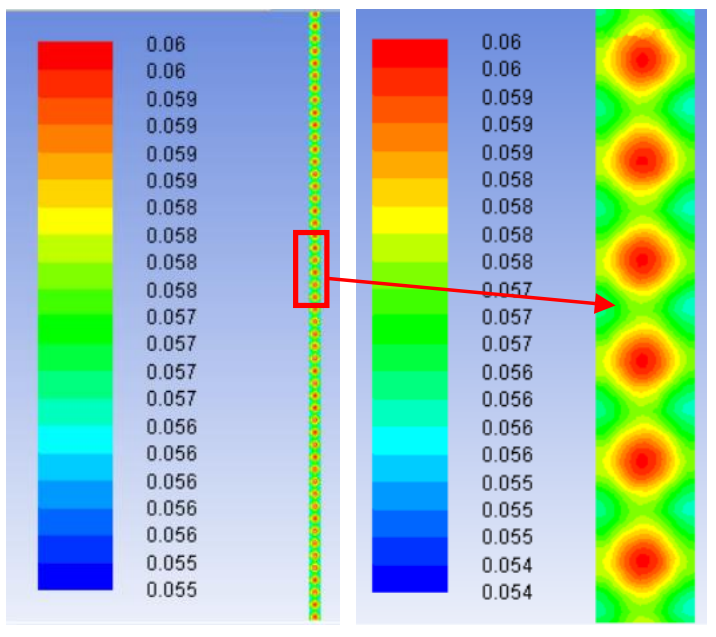

Fig. 8. Velocity fields imported in the TSC model

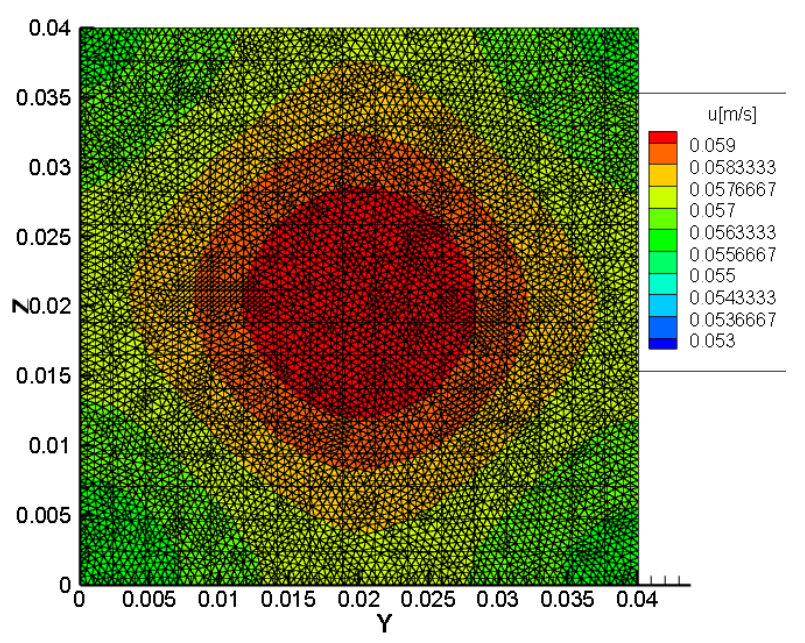

Fig. 9. Velocity fields imported from the previous model studied and processed in Tecplot 

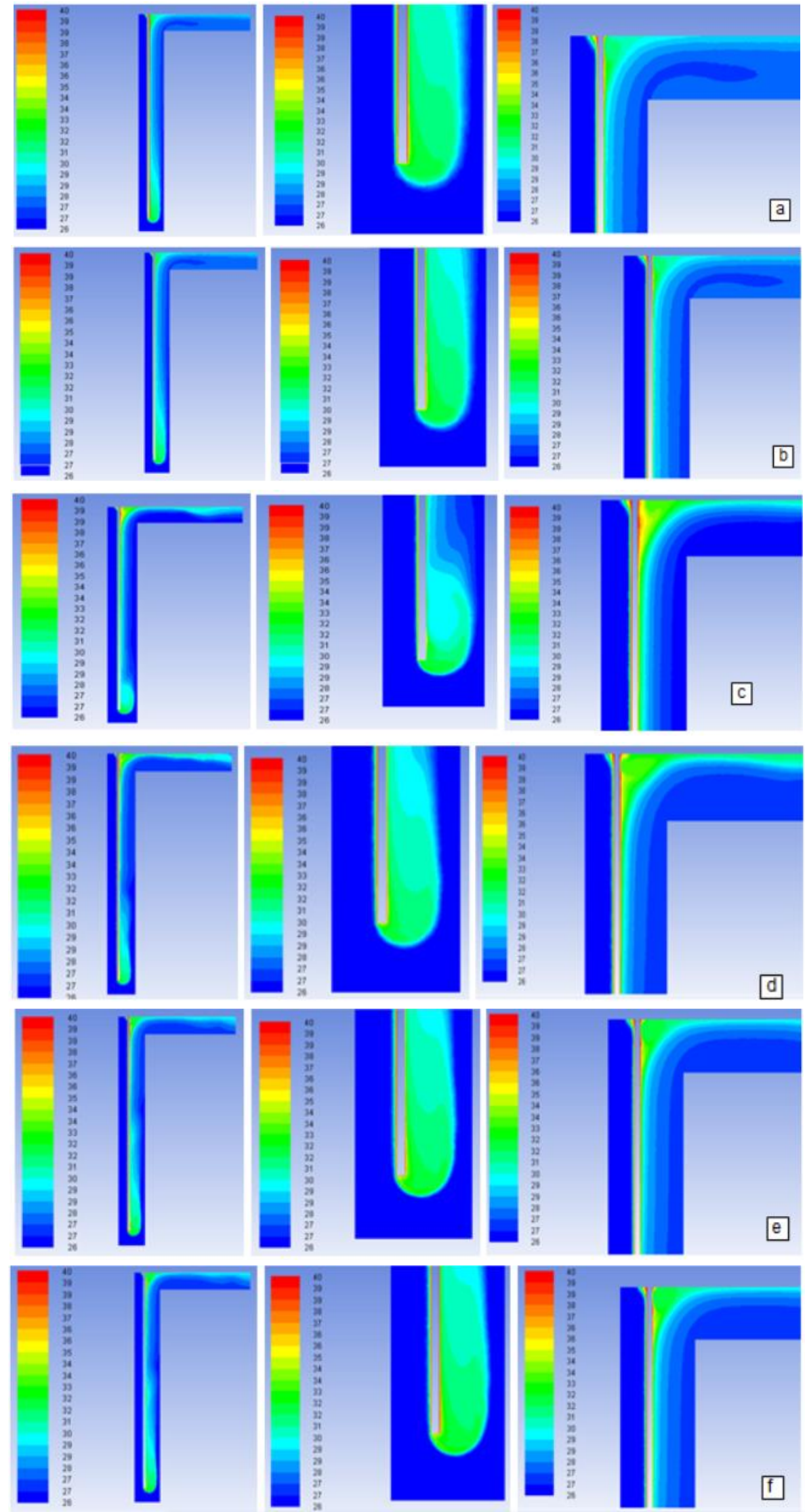

Fig. 10. Temperature fields in longitudinal plane (symmetry): a) $0.2(0.18)$, b) $0.66(0.61)$, c) $1.3(0.7)$, d) $2.8(1)$, e) $5(2.5)$, f) $6(3.5)$ million elements (the axis represents temperature in ${ }^{\circ} \mathrm{C}$ )

\footnotetext{
* Corresponding author: andrei.s.bejan $@$ gmail.org
} 


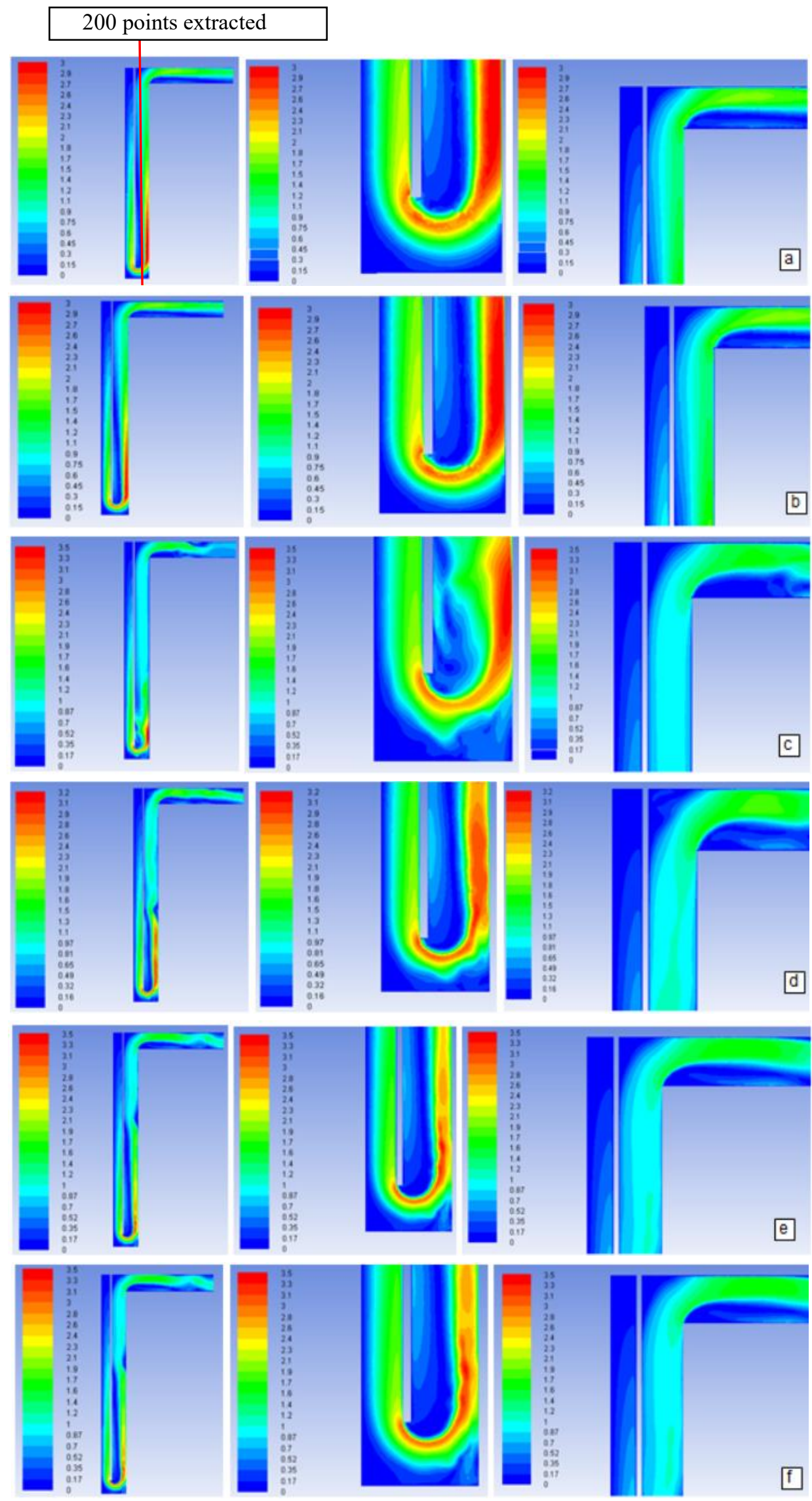

Fig. 11. Velocity fields in longitudinal plane (symmetry): a) $0.2(0.18)$, b) $0.66(0.61)$, c) $1.3(0.7)$, d) 2.8 (1), e) 5 (2.5), f) 6 (3.5) million elements (the axis represents velocity in $\mathrm{m} / \mathrm{s}$ ) 


\section{Results and discussions}

With respect to the above-mentioned data, we have performed numerical simulations for the six computational grids and the results for the steady state study are presented below.

Figure 10 shows the temperature fields in longitudinal plane (XY) for the six meshing levels chosen. It can be observed that for 0.2 and 0.66 million cells the temperature distribution is relatively similar and uniform and starting with 1.3 million cells it begins to change. However, starting with the 2.8 million cells, the temperature distribution begins to normalize again, while at 5 million and 6 million cells the results are virtually similar. It can be seen that at the bottom of the solar collector, the airflow temperature is higher due to the appearance of vortices and air circulation at a relatively low velocity, seen also at the top of the secondary air cavity. In the zones where the temperatures are lower, we can observe also high values of air velocities (Figure 11). The average outlet temperature obtained taking into account the boundary limits imposed (Table 1) is $29.3^{\circ} \mathrm{C}$ which means a rise in temperature of about $3.3{ }^{\circ} \mathrm{C}$ for the presented case studied in steady state regime (discharge period).

Figure 11 shows the velocity fields in the longitudinal planes $(\mathrm{XY})$ for the six meshing levels. It can be noticed that for 0.2 and 0.66 million cells, the velocity distribution is also relatively similar and uniform, while starting with 1.3 million cells it changes similarly to the temperature field. However, starting with the 2.8 million cells, the velocity distribution begins to stabilise, while the results of 5 million and 6 million cells are virtually similar. Moreover, we can observe that at the bottom of the solar collector in the second cavity, the air velocity near the wall increases because of the PCMs obstacle, which causes the apparition of vortices in the vicinity of the chicane and determines the temperature to increase locally (Figure 12).

After analysing the temperature and velocity fields from a qualitative point of view, we compared also one velocity profile in transversal plane for all six meshing levels by using a quantitative approach. To do this, we extracted 200 points from XY plane, at $\mathrm{X}=0.2 \mathrm{~m}$ (Figure 11a) and we emphasised the velocity magnitude variation on a transversal profile (Figure 13) for all the six meshing levels. We can observe that the results are similar. The velocity profiles are similar for 0.2 and 0.66 million cells, while from 1.3 and 2.8 million cells the profiles are different. From 5 million cells we can notice that the differences are very small compared with the 6 million cells mesh.

After conducting the mesh independency study, taking into account the above-mentioned aspects, we decided to use for the numerical model, which will be validated and used in the further studies, the 5 million element spatial mesh because it determines a mesh independent solution (figure 14). This grid is complementary to the mesh presented in Figure 6e and highlights the mesh obtained for the PCMs cavity.

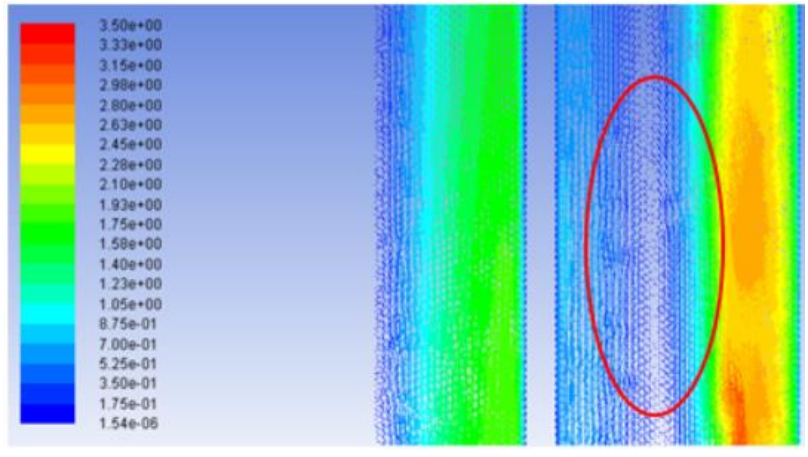

Fig. 12. Velocity vectors in longitudinal plane - vortices

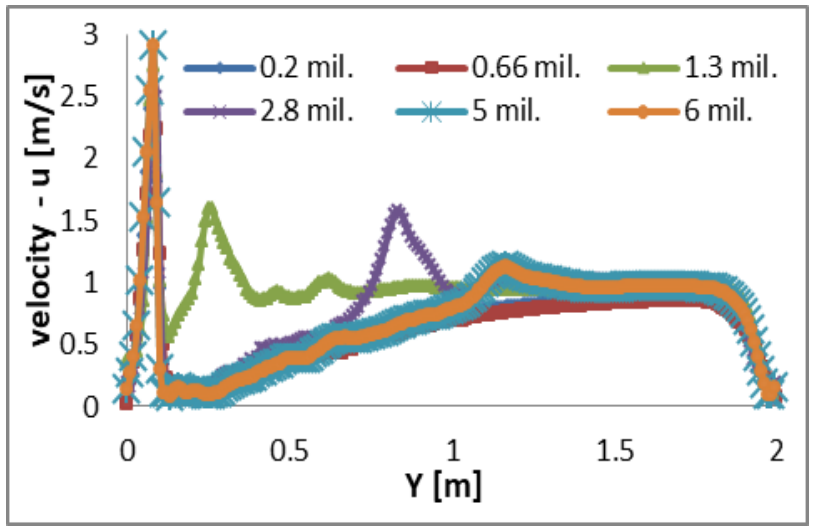

Fig. 13. Velocity profile on $Y$ axis, in $X Y$ plane at $X=0.2 \mathrm{~m}$ for all six meshing levels
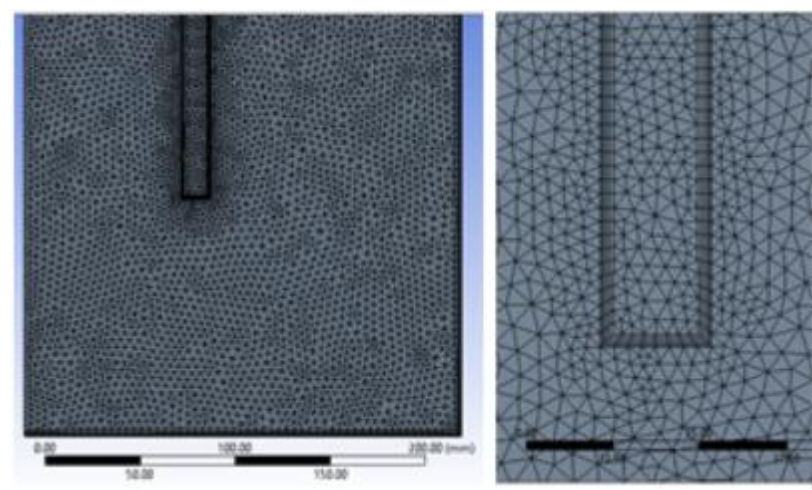

Fig. 14. The spatial mesh that will be used for further studies the final case of TSC with PCMs (5 million elements)

\section{Conclusions}

The present paper aims to analyse the mesh independency study of a transpired solar collector with integrated phase changing materials and its preliminary results. The paper is part of a comprehensive study regarding numerical modelling of TSCs with integrated PCMs.

After realising the geometrical model we built six different meshing levels and for each of them we imposed the corresponding boundary conditions resulted from the experimental studies conducted. By comparing the temperature and velocity fields obtained, from both perspectives (qualitative and quantitative), we can conclude that the 5 million elements mesh (2.5 million 
cells for the air cavity and 2.5 million cells for the PCM layer) determines a solution independent of the meshing quality. Moreover, preliminary studies conducted in steady state regime shows that considering a $26^{\circ} \mathrm{C}$ inlet air temperature and $40{ }^{\circ} \mathrm{C}$ PCMs temperature, the rise in temperature reached is about $3.3{ }^{\circ} \mathrm{C}\left(29.3{ }^{\circ} \mathrm{C}\right)$.

Further studies will analyse the validation of the numerical model in transient regime by comparing its results with the experimental results. Moreover, parametrical studies will be conducted in order to optimise the TSC characteristics: different PCMs quantities, different airflows, different types of PCMs etc.

\section{Acknowledgements}

This work was supported by a grant of the Romanian National Authority for Scientific Research, CNCS - UEFISCDI, project number PN-III-P1-1.2-PCCDI-2017-0391.

\section{References}

1. UNEP. Buildings and Climate Change Summary for Decision-Makers, 2009 [cited September 2019; Available from: http://www.unep.org/sbci/pdfs/SBCIBCCSummary.pdf].

2. C. Reichl, K. Kramer, C. Thoma, P. Benovsky, and T. Lemée, Solar Energy, 120 450-463 (2015).

3. C.-M. Lai and S. Hokoi, Building and Environment, 91 152-165 (2015).

4. A. Shukla, D.N. Nkwetta, Y.J. Cho, V. Stevenson, and P. Jones, Renewable and Sustainable Energy Reviews, 16 (6), 3975-3985 (2012).

5. D.N. Nkwetta and F. Haghighat, Sustainable Cities and Society, 10 87-100 (2014).

6. B. Molineaux, B. Lachal, and O. Guisan, Solar Energy, 53 (1), 27-32 (1994).

7. M.A. Leon and S. Kumar, Solar Energy, 81 (1), 6275 (2007).

8. T. Zhang, Y. Tan, H. Yang, and X. Zhang, Applied Energy, 165 707-734 (2016).

9. C. Dymond and C. Kutscher, Solar Energy, 60 (5), 291-300 (1997).

10. L.H. Gunnewiek, K.G.T. Hollands, and E. Brundrett, Solar Energy, 72 (4), 317-325 (2002).

11. F. Bode, S. Kodjovi, M. Amina, and N. Ilinca, Scientific Bulletin - University Politehnica of Bucharest, Series D: Mechanical Engineering, 76 (12), 8 (2014).

12. A. Meslem, I. Nastase, F. Bode, and C. Beghein, The International Journal of Ventilation, 11 (3), 16 (2012).

13. A. Meslem, F. Bode, I. Nastase, and O. Martin, Modern Applied Science, 6 (12), 15 (2012).

14. G.W.E. Van Decker, K.G.T. Hollands, and A.P. Brunger, Solar Energy, 71 (1), 33-45 (2001).
15. C. Croitoru, I. Nastase, F. Bode, and A. Meslem, Solar Energy, 131 21-29 (2016).

16. C. Croitoru, I. Nastase, I. Voicu, A. Meslem, and M. Sandu, Energy Procedia, 85 149-155 (2016).

17. C. Arkar, T. Šuklje, B. Vidrih, and S. Medved, Applied Thermal Engineering, 95 281-287 (2016).

18. A.S. Bejan, T. Catalina, D.B. Mocanescu, and A. Ene, E3S Web of Conferences - EENVIRO 2018, 8504007 (2019).

19. N. Soares, J.J. Costa, A.R. Gaspar, and P. Santos, Energy and Buildings, 59 82-103 (2013).

20. M. Badache, D. Rousse, S. Halle, G. Quesada, and Y. Dutil, Energy Procedia, 30 19-28 (2012).

21. M. Gholampour and M. Ameri, Appl. Energy 164, 164 837-856 (2016).

22. A.S. Bejan, F. Bode, T. Catalina, and C. Teodosiu, E3S Web of Conferences - EENVIRO 2018, 85 02017 (2019).

23. A.S. Bejan, F. Bode, C. Teodosiu, C. Croitoru, and I. Nastase, E3S Web of Conferences - EENVIRO 2018, 8502013 (2019).

24. ANSYS, Manual - Ansys Fluent Chapter 4.1.5. The k-omega and SST Models.

25. Y. Ji, CFD Letters, Vol. 6 (1) (2014). 